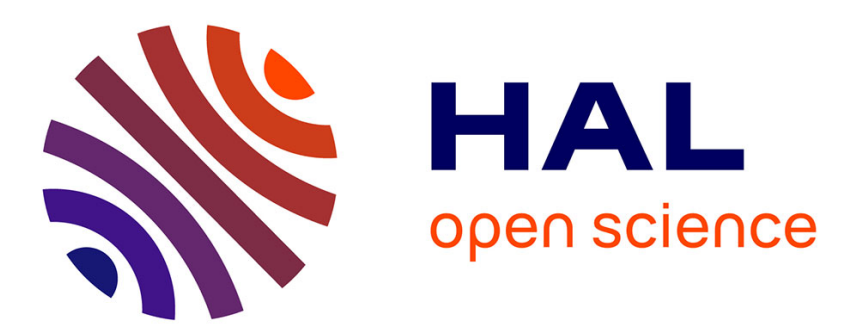

\title{
Experimental On-Body Fading and Breathing Doppler Characterization on Human Torso at $60 \mathrm{GHz}$
}

\author{
Luca Petrillo, Theodoros Mavridis, Julien Sarrazin, Aziz Benlarbi-Delai, \\ Philippe de Doncker
}

\section{- To cite this version:}

Luca Petrillo, Theodoros Mavridis, Julien Sarrazin, Aziz Benlarbi-Delai, Philippe de Doncker. Experimental On-Body Fading and Breathing Doppler Characterization on Human Torso at $60 \mathrm{GHz}$. International Conference on Body Area Networks, Sep 2014, London, United Kingdom. hal-01060596

\section{HAL Id: hal-01060596 \\ https://hal.sorbonne-universite.fr/hal-01060596}

Submitted on 3 Sep 2019

HAL is a multi-disciplinary open access archive for the deposit and dissemination of scientific research documents, whether they are published or not. The documents may come from teaching and research institutions in France or abroad, or from public or private research centers.
L'archive ouverte pluridisciplinaire HAL, est destinée au dépôt et à la diffusion de documents scientifiques de niveau recherche, publiés ou non, émanant des établissements d'enseignement et de recherche français ou étrangers, des laboratoires publics ou privés. 


\title{
Experimental On-Body Fading and Breathing Doppler Characterization on Human Torso at $60 \mathrm{GHz}$
}

\author{
Luca Petrillo \\ OPERA Dpt. - Wireless \\ Communications Group \\ Université Libre de Bruxelles \\ B-1050 Brussels, Belgium \\ Ipetrill@ulb.ac.be
}

\author{
Short Paper
}

\author{
Theodoros Mavridis \\ OPERA Dpt. - Wireless \\ Communications Group \\ Université Libre de Bruxelles \\ B-1050 Brussels, Belgium \\ tmavridi@ulb.ac.be
}

\author{
Julien Sarrazin \\ UR2, L2E Dept. \\ Sorbonne Universités, UPMC \\ Univ Paris 06 \\ F-75005 Paris, France \\ julien.sarrazin@upmc.fr
}

\author{
Aziz Benlarbi-Delaï \\ UR2, L2E Dept. \\ Sorbonne Universités, UPMC \\ Univ Paris 06 \\ F-75005 Paris, France \\ Philippe De Doncker \\ OPERA Dpt. - Wireless \\ Communications Group \\ Université Libre de Bruxelles \\ B-1050 Brussels, Belgium \\ aziz.benlarbi_delai@upmc.fr pdedonck@ulb.ac.be
}

\begin{abstract}
This paper studies temporal fading and the Doppler effect due to breathing at $60 \mathrm{GHz}$ on the front side of an human torso through experimental results obtained in anechoic environment. The temporal fading is experimentally investigated and a model is proposed to characterized it as function of the distance between transmitter and receiver. Doppler spectrum due to breathing is characterized and modeled for specific links on the torso affected by inflation and deflation. Measurements and results are presented for both horizontal and vertical polarizations.
\end{abstract}

\section{Categories and Subject Descriptors}

[Millimeter-wave Body Area Networks (MilliBAN)]

\section{Keywords}

Millimeter Wave Measurement, Electromagnetic Propagation

\section{INTRODUCTION}

Wireless Body Area Networks (WBAN) have gained the interested of the scientific community over the past years [3]. The propagation between on-body communicating devices has been widely studied around $2.4 \mathrm{GHz}$ [13] because of the maturity of the wireless technology at this frequency. However, the emergence of $60 \mathrm{GHz}$ communicating systems [12] encourages the study and development of new $60 \mathrm{GHz}$ Body Area Networks (BAN) [1]. Static propagation models for off-body [8] and on-body [11] at $60 \mathrm{GHz}$ have been published and a skin-equivalent phantom has been proposed to validate plane-propagation models [2]. Specific link to link channels at $60 \mathrm{GHz}$ have been investigated and path loss and fading have been studied $[9,10]$. This communication studies the temporal fading and Doppler effetc due to breathing on the front side of the torso at $60 \mathrm{GHz}$ through experimental results obtained in anechoic environment. Both vertical and horizontal polarizations have been investigated.

\section{MEASUREMENT CAMPAIGN}

An experimental campaign has been carried out on the front side of the torso of a person, whose characteristics are resumed in table 1. An anechoic chamber has been chosen as the measurement environment in order to avoid reflections from walls, roof, floor and furniture. An Agilent E8361C Vector Network Analyser (VNA) has been used to collect the measures and it has been placed inside the anechoic chamber to reduce the length of the coaxial cables and then reduce the losses. The VNA has been set on continuous wave mode and it delivered a transmitted power of $0 \mathrm{dBm}$. Absorbing panels have been placed around the VNA. U-Band open wave-guide antennas have been chosen as radiating element and probe. We ensured that the open waveguides were oriented towards each other while collecting measurements, in order to prevent mis-alignment. Moreover, effects of small mis-alignments, which cannot be avoided, is palliated by the relative large beamwidth of open waveguides used as antennas in the azimuthal direction. A power amplifier with a gain of $30 \mathrm{~dB}$ at $60 \mathrm{GHz}$ has been used at transmission side to raise link budget.

Measurement have been performed for both vertical (normal to the body surface) and horizontal (longitudinal to the body surface) polarizations. 
Table 1: Physical quantities of the body

\begin{tabular}{|c|c|}
\hline Quantity & Value \\
\hline Gender & Male \\
Height & $172 \mathrm{~cm}$ \\
Weight & $60 \mathrm{Kg}$ \\
Torso Perimeter & $86 \mathrm{~cm}$ \\
\hline
\end{tabular}

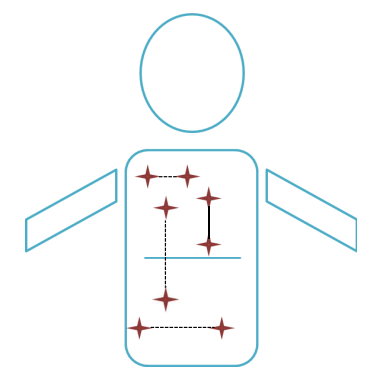

Figure 1: Measurement scheme. Stars correspond to measurement points on the front of torso. We depicted horizontal and vertical links of different lengths, on the chest, on the abdomen and one vertical chest-abdomen link. The horizontal line represents diaphragm and separate chest from abdomen.

\section{TEMPORAL FADING}

To investigate temporal fading, five particular distances between antennas have been chosen: 5, 10, 15, 20 and $25 \mathrm{~cm}$. For each distance, we took different realizations of the measurements: vertical and horizontal links, with respect to the human body, were investigated, so that for each distance and for each polarization we took forty measurements. The positions have been chosen in order to have equal numbers of measurement on the chest and on the abdomen, as well as vertical and horizontal links. So, for example, for vertical polarization and for $5 \mathrm{~cm}$ between the antennas, we measured 10 vertical and 10 horizontal links on the chest, 10 vertical and 10 horizontal links on the abdomen. For 20 and $25 \mathrm{~cm}$ distances, vertical measurements correspond to 20 chest-abdomen links. For the distance $25 \mathrm{~cm}$, horizontal measurements have not been taken, since the torso of the person under test (PUT) was not sufficiently large to obtain such distance. A scheme is shown in Fig. 1, where stars linked by a dashed line indicate a measure for a particular distance, spot on the PUT and orientation of the link. We have schematically indicated chest and abdomen by an horizontal line representing the diaphragm.

Each measurement has been conducted during 10 seconds which is equivalent to 150 temporal acquisitions. The antennas were located at $2 \mathrm{~cm}$ from the body surface for both transmitter (TX) and receiver (RX) antenna. The measurement parameters are summarized in table 2 .

Different distributions (Normal, Lognormal, Gamma, Nakagami, Rayleigth, Rice, Weibull and Uniform) were investigated. For each model, estimation results were evaluated through Mean Square Error (MSE). Results are plotted in Fig. 2. Lognormal distribution is then adopted, which permits to represent temporal fading in $\mathrm{dB}$ by a normal distribution. The standard deviation (STD) is evaluated for
Table 2: Parameters of the measurement campaign

\begin{tabular}{|c|c|}
\hline Symbol & Value \\
\hline$f$ & $60 \mathrm{GHz}$ \\
Measurement time & $10 \mathrm{~s}$ \\
Acquisitions per measurement & 150 \\
Body-antenna distance & $2 \mathrm{~cm}$ \\
Reference distances & $5,10,15,20$ and $25 \mathrm{~cm}$ \\
\hline
\end{tabular}

Table 3: Normal fading parameters

\begin{tabular}{|c|c|c|c|}
\hline Channel & $n_{\sigma_{F}}$ & $\sigma_{F_{0}}$ & $\sigma_{\text {sigma }}$ \\
\hline V. Pol. V. links & 0.028 & 0.53 & 0.67 \\
V. Pol. H. links & 0.073 & 0.43 & 0.98 \\
H. Pol. V links & 0.053 & 0.66 & 1.15 \\
H. Pol. H links & 0.086 & 0.35 & 0.9 \\
\hline
\end{tabular}

each polarization, link and distance. It is increasing with the distance, as it has been observed at lower frequency [6]. Therefore, we characterize it by:

$$
\begin{aligned}
\sigma_{F} & =\mu_{\sigma_{F}}+\sigma_{\sigma_{F}} \mathcal{N}(0,1) \\
\mu_{\sigma_{F}} & =\sigma_{F_{0}}+n_{\sigma_{F}}\left(d-d_{0}\right)
\end{aligned}
$$

Where $\mathcal{N}(0,1)$ is a normal process of zero mean and variance equal to 1 . Values of $n_{\sigma_{F}}, \sigma_{F_{0}}, \sigma_{\sigma_{F}}$ for $d_{0}=5 \mathrm{~cm}$ are reported in Table 3 .

The increasing rate for horizontal links is greater than for vertical links, which means that on-body channels at $60 \mathrm{GHz}$ are more sensitive to body shadowing caused by its curvature than to the polarization. Moreover, fading of $60 \mathrm{GHz}$ onbody channels on the front side of the torso for a subject at rest is quite pronounced, as the values shown in Table 3 are of the same order of magnitude of those found at 2.45 $\mathrm{GHz}$ for a subject swinging his arms [5]. This is because of the small wavelength at $60 \mathrm{GHz}$, which greatly affects the channel spatial variation due to different positions on the front side of the human torso, small movements and breathing.

Fig. 3 shows two examples of measurements in the temporal domain, normalized with respect to their mean values $\overline{S_{21}}$. The first one (solid line) corresponds to a distance between antennas equal to $15 \mathrm{~cm}$, vertical polarization and vertical link on the chest. This is almost a static channel, where temporal fading follows a normal distribution in logarithmic scale. On the other hand, the dashed line clearly reveals a periodic movement that affects the channel between the antennas: it corresponds to the same $15 \mathrm{~cm}$ distance between antennas for the same polarization and for an horizontal link on the chest. The breathing affects the channel, since the chest naturally expands and compress, varying the distance between antennas. A similar effect is experimentally found for vertical links greater than $20 \mathrm{~cm}$ (chest-abdomen), caused by stomach's inflating and deflating. For links affected by respiration, we observe a periodic temporal variation of the channel. Therefore, in the Doppler 

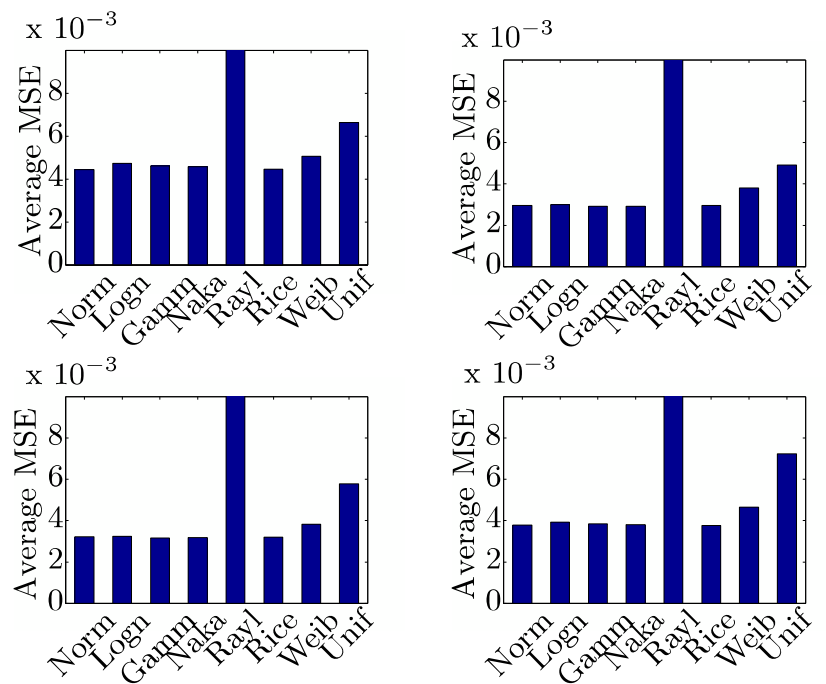

Figure 2: Average MSE of common distribution fits. The above row presents the vertical polarization and the below row presents the horizontal polarization. The left column is the vertical links while the right column is the horizontal links.

spectrum we should notice breathing Doppler frequency and its harmonics.

\section{DOPPLER EFFECT DUE TO BREATH- ING}

The Doppler spectrum of a propagation channel models the mobility of the transmitter, the receiver or the surroundings scatterers. The inflation and deflation of the thorax and the abdomen form the Doppler spectra of the front of the torso. To characterize the Doppler spectrum we took a new set of measurements by increasing the acquisition length, which has been set to $30 \mathrm{sec}$. We have investigated an horizontal link on the chest and a vertical chest-stomach link. The Doppler spectrum is estimated with the Welch periodogram method [14] by normalizing the channel gains to 0 $\mathrm{dB}$. The average Doppler Power Spectral Density (PSD) of a typical body link affected by breathing is shown in Fig. 4: the zero Doppler frequency is found because $S_{21}$ oscillates around a mean value, whereas the peaks are at fundamental frequency, which is nearly $0.18 \mathrm{~Hz}$, and its harmonics. The breathing cycle then lasts approximately $5 \mathrm{sec}$, which it is considered as normal at rest [4]. Following [7], we propose a model for respiration Doppler PSD:

$$
\operatorname{PSD}\left(f_{D}\right)=\frac{1}{1+s f_{D}^{2}} \sum_{m=1}^{\infty} \frac{x}{2^{m}} \frac{1}{1+4^{m} a+s^{2}\left(f_{D} \pm m f_{0}\right)^{4}}
$$

where $f_{0}$ is the breathing frequency, $s$ describes the overall Doppler spread, $a$ describes the local spectrum spread at the harmonic frequencies and $x$ is the decaying of the Doppler PSD at $f_{0}$ compared to $f_{D}=0 \mathrm{~Hz} .2^{m}$ is an extra fitting of the spectrum decrease between adjacent frequency harmonics. The parameters' values are sequentially estimated by minimal square error (MSE) estimator. The parameters

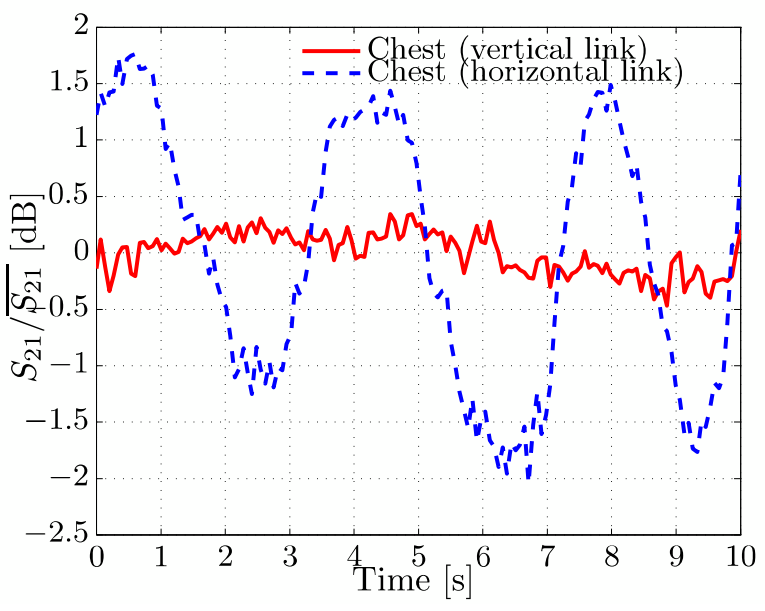

Figure 3: Channel fading amplitude for two measurement samples of $S_{21}$ normalized by their mean values.

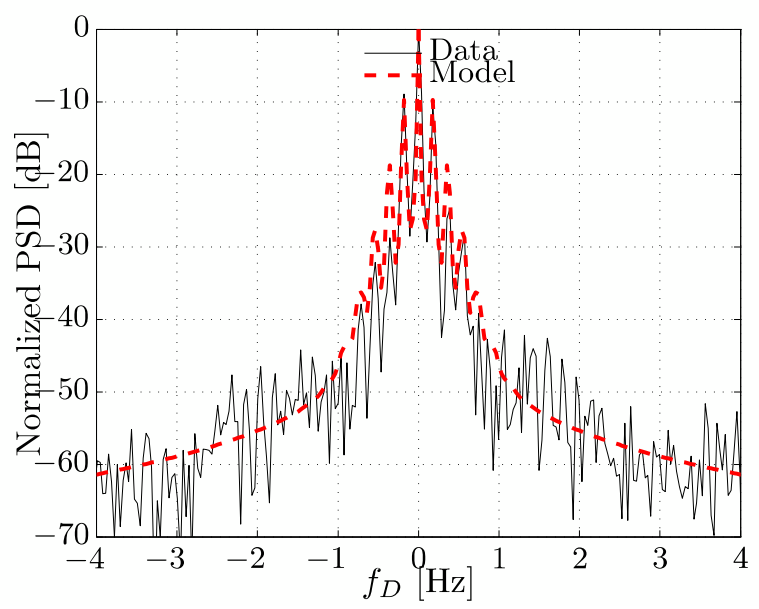

Figure 4: Normalized Doppler PSD and model of body link affected by breathing influence (vertical polarization, chest).

estimation is shown in Table 4 for different torso links.

The Doppler PSD is concentrated with $4 \mathrm{~Hz}$, since the subject is standing still and breathing, which has a period comprised between 0.18 and $0.25 \mathrm{~Hz}$ at rest, is mostly responsible of the channel variations. Moreover, the channel variation is strongly influenced by the relative position of transmitter and receiver, which varies following inflation and deflation. For that reason, peaks at fundamental breathing frequencies posses strong magnitude values and only three harmonics of the fundamental breathing frequency are clearly visible in the Doppler PSD.

\section{CONCLUSION}

In this paper, we presented the results of a measurement campaign conducted at $60 \mathrm{GHz}$ in anechoic environment on the front side of the torso of a human subject for both vertical and horizontal polarizations. Temporal fading is dis- 
Table 4: Doppler PSD parameters

\begin{tabular}{|c|c|c|c|c|}
\hline Measurement & $f_{0}[\mathrm{~Hz}]$ & $s\left[\mathrm{~Hz}^{-2}\right]$ & $x[W]$ & $a$ \\
\hline V. Pol. chest & 0.18 & 85980 & 339 & 287 \\
H. Pol. chest & 0.2 & 77150 & 281.9 & 75.8 \\
V. Pol. chest-abdomen & 0.18 & 81450 & 933.5 & 673.7 \\
H. Pol. chest-abdomen & 0.25 & 63840 & 168.2 & 11.9 \\
\hline
\end{tabular}

cussed and investigated. Normal distribution in $\mathrm{dB}$ scale is used to model fading and a model for the STD is proposed. Experimental results reveal that horizontal links are more subject to fading than vertical links because of the shadowing of the human torso's curvature, which overcome polarization influence.

Doppler spectrum is evaluated to put in evidence breathing effect on chest and abdomen-chest channels. An analytical model is introduced and estimated parameters are reported. The Doppler PSD peaks at fundamental breathing frequency posses strong magnitude values, since breathing causes the transmitter and receiver to move following inflation and deflation. Only three harmonics are then clearly identified in the PSD.

Future works are needed to investigate the effect of body motion (walking, running, etc.) on the fading of on-body channels on the front side of the torso at $60 \mathrm{GHz}$.

\section{Acknowledgment}

The authors would like to thank Prof. B. Huyart and Mr A. Khy from Telecom ParisTech for their helpful advice and willingness.

\section{REFERENCES}

[1] S. Alipour, F. Parvaresh, H. Ghajari, and F. Donald. Propagation characteristics for a $60 \mathrm{ghz}$ wireless body area network (wban). In Military Comm. Conf., MILCOM 2010, pages 719-723. IEEE, 2010.

[2] N. Chahat, M. Zhadobov, and R. Sauleau. Skin-equivalent phantom for on-body antenna measurements at $60 \mathrm{ghz}$. In Antennas Propag. (EUCAP), 2012 6th European Conference on, pages 1362-1664, March 2012.

[3] P. S. Hall and Y. Hao. Antennas and propagation for body centric communications. In Antennas and Propagation, 2006. EuCAP 2006. First European Conference on. IEEE, 2006.

[4] W. Lindh, M. Pooler, C. Tamparo, B. Dahl, and J. Morris. Delmar's comprehensive medical assisting: administrative and clinical competencies. Cengage Learning, 2013.

[5] L. Liu. Cooperative Wireless Channel Characterization and Modeling. PhD thesis, École Polytechnique, 2012.

[6] L. Liu, R. D'Errico, L. Ouvry, P. De Doncker, and C. Oestges. Dynamic channel modeling at $2.4 \mathrm{ghz}$ for on-body area networks. Advances in Electronics and Telecom.-Radio Comm. Series: Recent Advances in Wireless Comm. Networks, 2(4), 2011.

[7] L. Liu, S. Van Roy, F. Quitin, P. De Doncker, and C. Oestges. Statistical characterization and modeling of doppler spectrum in dynamic on-body channels. Antennas and Wireless Propagation Letters, IEEE, 12:186-189, 2013.

[8] T. Mavridis, L. Petrillo, J. Sarrazin, D. Lautru, A. Benlarbi-Delaï, and P. De Doncker. Theoretical and experimental investigation of a $60 \mathrm{GHz}$ off-body propagation model. IEEE Trans. Antennas Propag., 62(1):393-402, 2014.

[9] Y. Nechayev, C. Constantinou, S. Swaisaenyakorn, O. Rakibet, J. Batchelor, P. Hall, C. Parini, and J. Hunt. Use of motion capture for path gain modelling of millimetre-wave on-body communication links. Proceedings of ISAP2012, 3:5, 2012.

[10] Y. Nechayev, X. Wu, C. Constantinou, and P. Hall. Effect of body motion on propagation path gain at 60 ghz. In Antennas and Propagation (EUCAP), 2012 6th European Conference on, pages 3397-3401. IEEE, 2012.

[11] L. Petrillo, T. Mavridis, J. Sarrazin, D. Lautru, A. Benlarbi-Delaï, and P. De Doncker. Analytic creeping wave model and measurements for $60 \mathrm{GHz}$ body area networks. IEEE Trans. Antennas Propag., accepted.

[12] T. S. Rappaport, J. N. Murdock, and F. Gutierrez. State of the art in 60-ghz integrated circuits and systems for wireless communications. Proceedings of the IEEE, 99(8):1390-1436, 2011.

[13] N. F. Timmons and W. G. Scanlon. Analysis of the performance of ieee 802.15. 4 for medical sensor body area networking. In Sensor and ad hoc comm. and networks, 2004. IEEE SECON 2004. 2004 First Annual IEEE Comm. Society Conf. on, pages 16-24. IEEE, 2004.

[14] P. D. Welch. The use of fast fourier transform for the estimation of power spectra: a method based on time averaging over short, modified periodograms. IEEE Transactions on audio and electroacoustics, 15(2):70-73, 1967. 